\title{
First report of tubular corallites on Stylophora caused by a symbiotic copepod crustacean
}
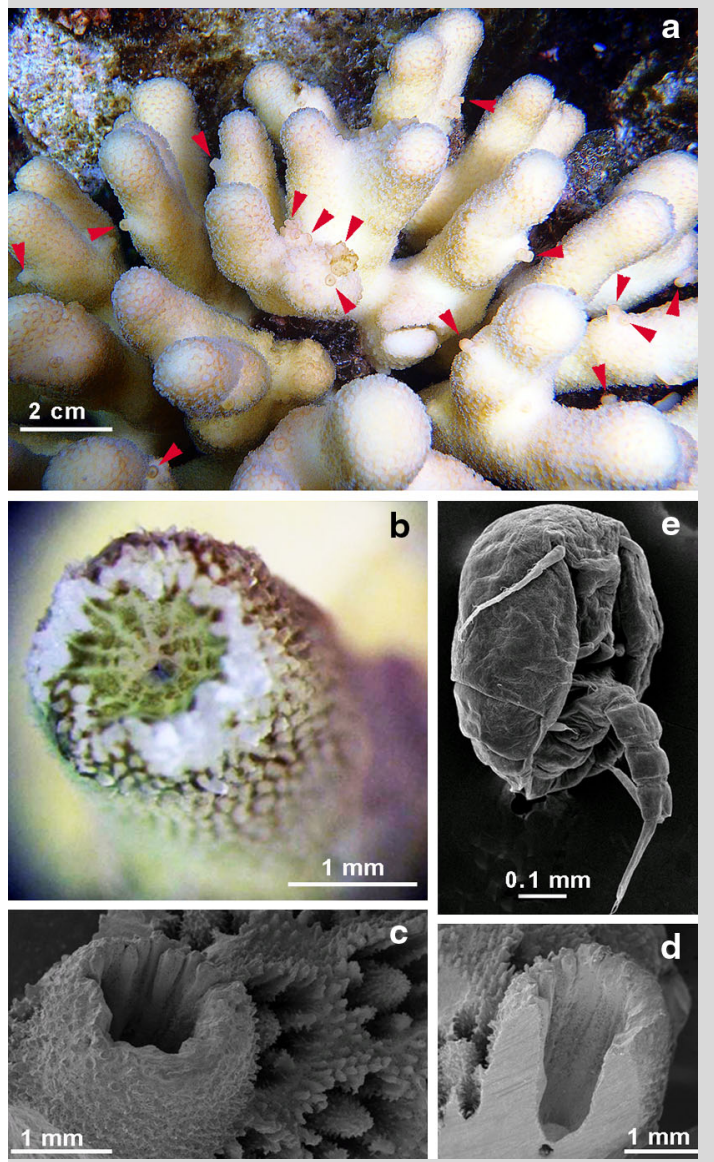

Fig. 1 a Stylopora pistillata colony heavily infected by symbiotic copepods inducing tubular-shaped modification of corallites (arrowed), Saudi Arabian part of the Red Sea. b Close-up of a modified corallite. $\mathbf{c}$ SEM of tubular corallite without septa and columella. d SEM of longitudinal section of the modified corallite. e SEM of a Spaniomolgus sp., endosymbiont of $S$. pistillata, female, ventrolateral view

cyclopoid copepods mainly associated with marine invertebrates. Beaufortia 2:121-133

\section{References}

Dojiri M (1988) Isomolgus desmotes, new genus, new species (Lichomolgidae), a gallicolous poecilostome copepod from the scleractinian coral Seriatopora hystrix Dana in Indonesia, with a review of gall-inhabiting crustaceans of anthozoans. J Crustacean Biol 8:99-109

Humes AG, Stock JH (1972) Preliminary notes on a revision of the Lichomolgidae, im IH, Yamashiro H (2007) Two species of poecilostomatoid copepods inhabiting galls on scleractinian corals in Okinawa, Japan. J Crustacean Biol 27:319-326

V. N. Ivanenko $(\bowtie) \cdot S$. V. Moudrova

Department of Invertebrate Zoology, Biological Faculty, Lomonosov Moscow

State University, Moscow 119992, Russia

e-mail: ivanenko@mail.bio.msu.ru; ivanenko.slava@gmail.com

J. Bouwmeester · M. L. Berumen

Red Sea Research Center, King Abdullah University of Science and Technology,

Thuwal 23955, Saudi Arabia

Received: 15 April 2014/ Accepted: 18 June 2014/Published online: 30 June 2014

(C) Springer-Verlag Berlin Heidelberg 2014
Coral Reefs (2014) 33:637

DOI $10.1007 / \mathrm{s} 00338-014-1186-6$ 